\title{
Efeito oxidativo do óxido nítrico e infertilidade no macho
}

\author{
Oxidative effect of nitric oxide and male infertility
}

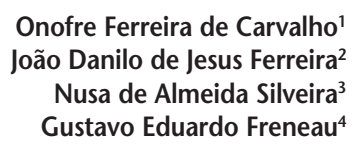

\begin{tabular}{l|l}
\multicolumn{1}{c|}{ Unitermos } & resumo \\
Óxido nítrico & $\begin{array}{l}\text { A capacidade de fertilização dos espermatozóides é dependente, entre outros fatores, da sua } \\
\text { motilidade e da integridade de sua membrana. As substâncias oxidativas, quando produzidas } \\
\text { Infertilidade }\end{array}$ \\
$\begin{array}{l}\text { Espermatozóide } \\
\text { entioxidantes }\end{array}$ & $\begin{array}{l}\text { expesso no organismo, em particular no líquido seminal, comprometem a motilidade do } \\
\text { capazes de promover estes efeitos é o óxido nítrico (ON), responsável pela mediação em } \\
\text { vários processos fisiológicos. O uso de terapias antioxidantes no tratamento de alguns tipos } \\
\text { de infertilidade deve ser feito com cautela, pois uma inibição muito severa poderá compro- } \\
\text { meter as taxas de ON e, conseqüentemente, irá influenciar outros mecanismos fisiológicos } \\
\text { dependentes de sua concentração. }\end{array}$
\end{tabular}

abstract

The capacity of fertilization of the sperm is dependent, among other factors, of the mobility and integrity of its membrane. The oxidative substances when produced in excess in the organism, in matter in the seminal liquid, they commit the mobility and viability of the sperm in their capacity of fertilization. One of the oxidative substance capable to promote these effects is the nitric oxide (NO), responsible for the mediation in several physiologic processes. The use of

antioxidant therapies in the treatment of some infertility types should be made with caution because it can commit the nitric oxide's levels and consequently, it will influence other physiologic mechanisms dependents of its concentration.

key words

Nitric oxide

Infertility

Sperm

Antioxidant

\section{Introdução}

A infertilidade masculina é uma síndrome multifatorial que abrange uma grande variedade de desordens, que podem ser congênitas ou adquiridas. As causas podem ser deficiência de gonadotropinas, aberrações cromossômicas, desordens genéticas, drogas, infecções genitais e doenças auto-imunes, entre outras (27). Acredita-se que alguns destes defeitos possam ser causados por uma excessiva produção de espécies de oxigênio reativo (EOR) no plasma seminal, entre eles o óxido nítrico (ON), levando a um estresse oxidativo. Este fato resulta em sérios danos aos esper- matozóides, como diminuição da motilidade e da viabilidade e comprometimento da capacitação e da reação acrossômica (1).

Em condições normais, as células somáticas contêm substâncias antioxidantes em seu citoplasma. Porém o espermatozóide, durante o período de maturação, perde a maioria de seu citoplasma, e, com isto, perde parte dos antioxidantes endógenos, ficando vulnerável à ação de EOR (28).

O objetivo do presente trabalho é apresentar algumas considerações sobre o efeito adverso do excesso
1. Biomédico; mestrando em Biologia pela Universidade Federal de Coiás (UFG); professor da Universidade Católica de Coiás (UCC). 2. Médico veterinário; mestrando em Biologia pela UFC.

3. Nutricionista; professora doutora do Departamento de Ciências Fisiológicas do Instituto de Ciências Biológicas da UFC. 4. Médico veterinário; professor doutor do Laboratório de Andrologia e Tecnologia do Sêmen do Departamento de Produção Animal da Escola de Veterinária da UFC. 
de ON e das terapias antioxidantes na capacidade reprodutiva do macho, no que diz respeito à fertilidade dos espermatozóides.

\section{Espermatogênese}

É um processo elaborado de diferenciação celular, responsável pela produção do gameta masculino (Figura 1). Ocorre no interior dos túbulos seminíferos presentes nos testículos. Inicia-se ainda na vida embrionária, com a formação das células germinativas, que permanecem em estado de latência até a puberdade, quando, sob o efeito das gonadotropinas hipofisárias, dão início ao processo de amadurecimento das células germinativas, com a formação dos espermatozóides (11).

\section{Mecanismo hormonal da espermatogênese}

O sistema reprodutor masculino é dependente de hormônios para regular sua função. A hipófise produz as gonadotropinas - hormônio folículo-estimulante (FSH) e hormônio luteinizante (LH) - sob o controle do hipotálamo. O FSH é requerido para a espermatogênese, e o LH estimula a produção de andrógenos testiculares pela célula de Leydig. O processo da espermatogênese é dependente da testosterona testicular para se manter, e os órgãos sexuais são ligados ao andrógeno para desenvolver suas atividades fisiológicas. A secreção de LH é regulada pelo mecanismo de feedback em função da concentração plasmática de testosterona circulante, que controla a secreção endócrina da hipófise e do hipotálamo. A secreção de FSH é regulada pela testosterona plasmática e também

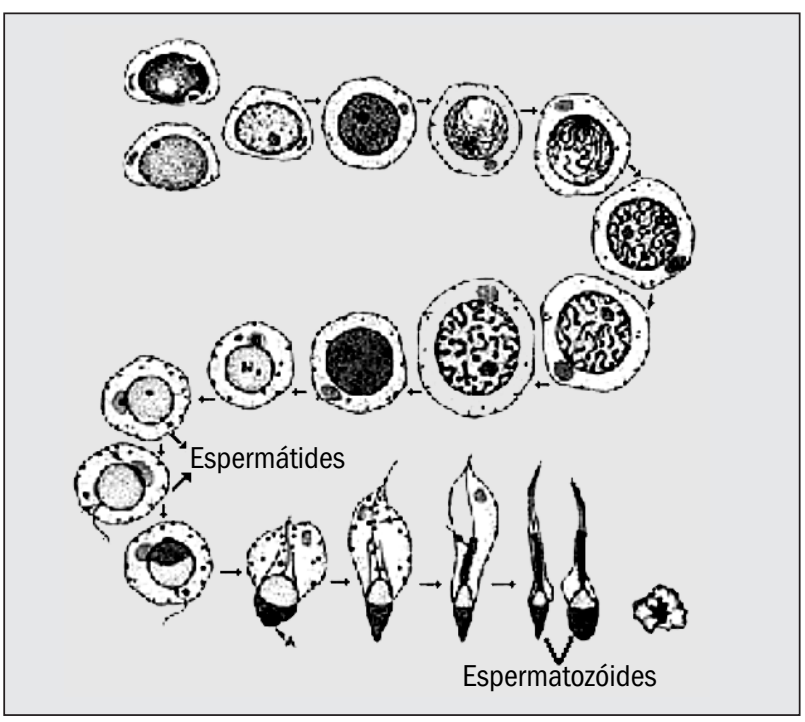

Figura 1 - Espermatogênese segundo Hermo e Clermont (11) pela inibina, um hormônio peptídico produzido pelas células de Sertoli. Esta alça endócrina é conhecida como eixo hipotalâmico-hipofisário-testicular. Além do controle hormonal, os órgãos reprodutivos são também sujeitos ao controle nervoso simpático e parassimpático. Isto é particularmente verdade para a função erétil do pênis, que está sob o controle parassimpático, e para a ejaculação, que está sob o controle simpático (29).

\section{Espermatozóide}

Os espermatozóides são células especializadas cuja função é fertilizar o óvulo. Eles apresentam três partes: uma, denominada "cauda", que é formada pelo flagelo, uma organela citoplasmática responsável pela motilidade espermática; a peça intermediária, uma região rica em mitocôndrias, que fornece energia aos movimentos flagelares; e a cabeça, onde se localiza o material genético e o acrossoma (Figura 2). O acrossoma é uma estrutura formada pelo aparelho de Golgi e constituída por enzimas, cuja função é auxiliar a penetração do espermatozóide na membrana externa do óvulo, evento necessário durante o processo de fertilização do óvulo (3).

\section{Capacitação espermática e reação acrossômica}

Os espermatozóides necessitam sofrer modificações funcionais e estruturais para serem capazes de fertilizar os oócitos. Habitualmente, o conjunto destas transformações é definido como "capacitação espermática" (4). Originalmente acreditava-se que estas mudanças ocorreriam apenas quando os espermatozóides estivessem em contato

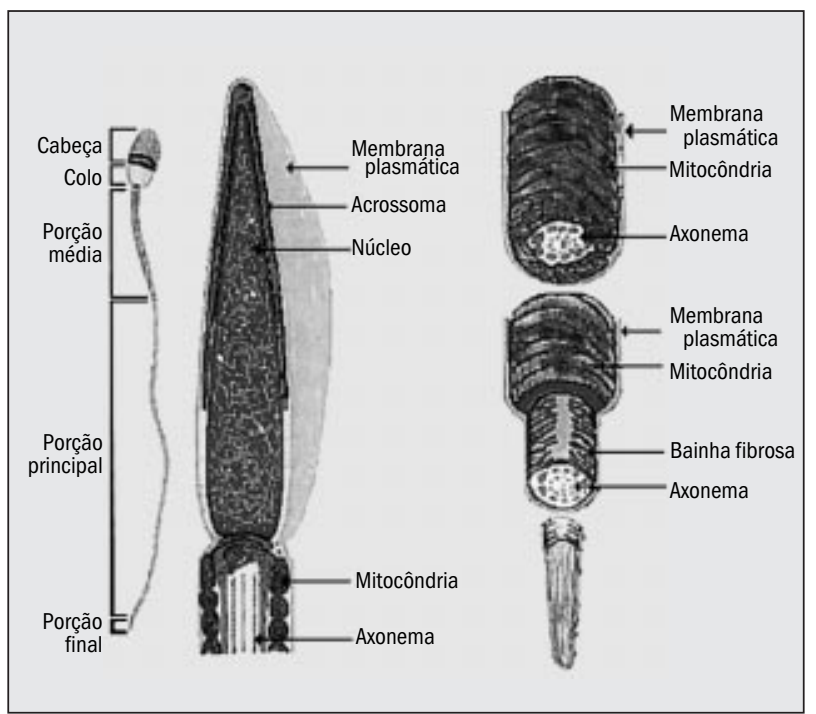

Figura 2 - Morfologia do espermatozóide: A. microscopia ótica; B. microscopia eletrônica - segundo Myles (21) 
com o trato genital feminino. Do ponto de vista fisiológico, essas alterações deveriam ser progressivas, já que os espermatozóides levam um tempo para atingir as trompas e iniciar sua interação com os oócitos. Em geral, os espermatozóides capacitados são aqueles que apresentam reação acrossômica. Inicialmente, essas modificações ocorrem no nível molecular da membrana plasmática e resultam em alterações morfológicas (reação acrossômica) e fisiológicas (hiperativação do flagelo).

A reação acrossômica é caracterizada pela fusão entre a membrana plasmática e a acrossomal externa, resultando em formação de vesículas e permitindo a liberação de enzimas do conteúdo acrossômico. Os espermatozóides necessitam reagir com componentes dos oócitos (células do cumulus, fluido folicular, zona pelúcida) para completar a reação acrossômica. O processo de capacitação depende de alterações da permeabilidade da membrana ligadas ao transporte dos íons cálcio (21).

\section{Fertilização}

A fecundação (fertilização) é um processo que se inicia com o contato entre o espermatozóide e o ovócito (óvulo) e finda com a fusão do material genético contido nestes gametas. Este contato se dá especificamente entre receptores presentes na zona pelúcida do ovócito e ligantes localizados na membrana citoplasmática do espermatozóide. O complexo receptor-ligante induz a reação acrossômica, que consiste na liberação das enzimas contidas no acrossoma, as quais têm a função de formar uma passagem para o espermatozóide, através da zona pelúcida, até a membrana citoplasmática do ovócito. O contato entre as membranas citoplasmáticas do espermatozóide e do ovócito induz, neste último, a reação cortical na qual ocorre a exocitose das enzimas contidas nos grânulos corticais, localizados na periferia do ovócito. As enzimas liberadas durante a reação cortical provocam modificações na zona pelúcida, levando ao seu endurecimento e à inativação dos receptores. Estas alterações, denominadas "reações zonais", impedem definitivamente, na maioria das espécies, a penetração de outro espermatozóide no ovócito (polispermia). O contato das membranas citoplasmáticas dos gametas induz, ainda, a ativação do ovócito, com a retomada da divisão meiótica que havia sido suspensa na metáfase II. Com a fusão das membranas citoplasmáticas, o material contido no espermatozóide é transferido para o ovócito. O material genético do espermatozóide (pró-núcleo masculino) e o do ovócito (pró-núcleo feminino) fundem-se e preparam-se para a primeira clivagem da célula-ovo ou zigoto (21).

\section{Óxido nítrico}

O óxido nítrico (ON) é um gás formado em meio aquoso através da conversão da arginina, na presença de oxigênio e diversos co-fatores, em citrulina e ON pela ação da óxido nítrico-sintetase (ONS) (Figura 3) (13). Sua molécula é lábil e de grande difusibilidade, sintetizada de forma regulada. O ON participa de mecanismos fisiológicos muito importantes, agindo como mensageiro intracelular no controle do tônus vascular, na neurotransmissão, na produção de hormônios, na diferenciação celular, na expressão gênica e na ativação de células do sistema imune (19). Estas ações dependem da produção local e da disponibilidade da ONS, já que o ON é rapidamente consumido (20). A enzima que controla a produção do ON foi encontrada sob três formas homólogas: iONS (indutora), eONS (endotelial) e nONS (neuronal) (22). A forma nONS está contida em neurônios que são encontrados em várias localizações no hipotálamo e, em particular, nos núcleos paraventricular e supra-óptico, cujos axônios se projetam para a eminência mediana e se estendem até o lobo neural da hipófise (18). O tipo iONS foi relatado em células do sistema imune. Sua atividade apresenta-se elevada em quadros inflamatórios, em função do aumento do número das células de defesa (16).

\section{Oxidação biológica}

A produção de EOR em espermatozóides está associada à função fisiológica normal, mas o descontrole e o excesso de EOR representam um dos maiores fatores relacionados com a infertilidade (2). Estudos recentes mostraram que entre $40 \%$ e $88 \%$ dos homens com baixa fertilidade apresentam elevados níveis de EOR no plasma seminal (15). Um dos oxidantes encontrados no plasma seminal é o

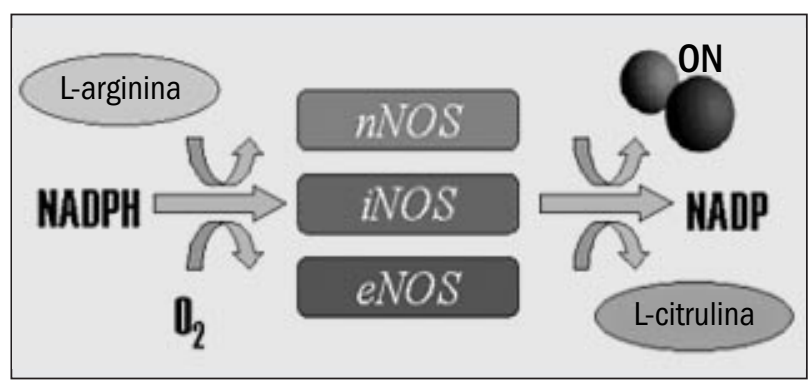

Figura 3 - Esquema de formação do óxido nítrico sob ação das isoenzimas da óxido nítrico-sintetase 
óxido nítrico. Várias evidências apontam para seu envolvimento na função espermática normal (10) e na disfunção espermática (24). Em situações de falha na regulação da ONS, ocorre uma excessiva produção de ON, que pode causar patologias aos espermatozóides, diminuindo a fertilidade (25). Estudos realizados por Moira et al. (19) demonstraram uma correlação negativa entre espermatozóides com ONS e a motilidade espermática. O excesso de oxidantes no plasma seminal prejudica a capacitação espermática e a reação acrossômica (6). Defeitos espermáticos funcionais foram identificados como uma das causas de infertilidade humana (27). Estes defeitos podem ser causados por uma excessiva produção de ONS ocorrida no plasma seminal, produzindo estresse oxidativo e resultando em sérios danos aos espermatozóides, como diminuição da motilidade e da viabilidade e aumento dos defeitos espermáticos (1). A capacitação espermática é essencial para a fertilização. Caracteriza-se pela hiperativação do espermatozóide e sua preparação para a reação acrossômica, necessária para o rompimento da membrana externa do óvulo (27).

O plasma seminal apresenta substâncias que têm ação antioxidante, sendo esse efeito denominado "capacidade antioxidante total" (CAT). Estas substâncias auxiliam a proteção dos espermatozóides contra a oxidação. Uma depressão na CAT implica infertilidade de machos (15). Exemplos de substâncias antioxidantes naturais são superóxido dismutase, catalase e sistema peroxidase/redutase, as quais têm um papel significativo na proteção do espermatozóide contra danos oxidativos (17).

\section{Oxidação e infertilidade}

\section{Efeitos oxidativos sobre o espermatozóide}

Todos os organismos aeróbicos requerem oxigênio para a sua sobrevivência. Porém, embora o oxigênio seja um elemento essencial, seus metabólitos, como o superóxido $\left(\mathrm{O}_{2}-\right)$, o peróxido de hidrogênio $\left(\mathrm{H}_{2} \mathrm{O}_{2}\right)$ e o radical oxidrila $(\mathrm{OH})$, são capazes de modificar o funcionamento celular de forma adversa, comprometendo mecanismos e arriscando a sobrevivência da célula. Estas EOR foram implicadas como um fator que contribui para a infertilidade masculina (7).

O espermatozóide humano é particularmente sensível à agressão de radicais livres que atacam ácidos graxos poliinsaturados, promovendo falha no mecanismo de correção do DNA. Células somáticas contêm antioxidantes dentro de seu citoplasma. Porém o espermatozóide perde a maioria de seu citoplasma durante a maturação, faltando, assim, mecanismos endógenos que regulem e realizem defesas enzimáticas, que são observadas em outros tipos celulares. Isto deixa os espermatozóides em uma desvantagem significativa. Mas eles são protegidos pelo protoplasma seminal, que contém uma abundância de enzimas antioxidantes, como os superóxidos dismutase e catalase, que removem EOR fundamentais, como $\mathrm{O}_{2}$ - e $\mathrm{H}_{2} \mathrm{O}_{2}$ (15).

\section{Efeitos sobre a motilidade do espermatozóide}

O óxido nítrico é um mediador funcional importante em vários sistemas fisiológicos, incluindo o sistema reprodutivo. Porém, quando gerado em quantidades excessivas por períodos longos, principalmente durante reações imunológicas, o ON é citotóxico e citostático para micróbios invasores, bem como para as células que o geram e os tecidos adjacentes. Pacientes com infecção da área urogenital podem apresentar uma redução da motilidade e da viabilidade espermática. É possível que a fertilidade reduzida nestes pacientes esteja relacionada à toxicidade induzida pelo $\mathrm{ON}$ no espermatozóide (23). Portanto a síntese excessiva de ON que acompanha a infecção e a inflamação pode ser um fator importante na mudança funcional dos espermatozóides, conduzindo-os a uma deficiência orgânica e acarretando a infertilidade (24).

\section{Efeito do ON no eixo hipotalâmico-hipofisário- testicular}

O óxido nítrico atua no hipotálamo, estimulando a liberação do hormônio liberador de gonadotropinas (GnRH) e inibindo a liberação de oxitocina. O GnRH, no nível hipofisário, estimula a liberação dos hormônios luteinizante e folículo-estimulante. Uma diminuição da concentração de ON hipotalâmico pode causar danos à função reprodutiva, já que ele é um dos responsáveis pelo funcionamento do eixo reprodutivo, sendo de fundamental importância para a reprodução normal (18).

\section{Terapia antioxidante}

Com o objetivo de melhorar a eficiência reprodutiva, são utilizados alguns antioxidantes, entre eles as vitaminas $A, C$ e E. Estas previnem, nas fêmeas, a diminuição da taxa de ovulação associada com a idade e neutralizam os problemas de distribuição e segregação cromos- 
sômica na primeira divisão meiótica durante a formação do óvulo (26). Em machos oligospérmicos, a administração de vitaminas C e E (200mg) por um período de dois meses aumentou a concentração espermática no ejaculado (14). Dawson et al. (5) mostraram que, após a administração de $1.000 \mathrm{mg}$ de vitamina $\mathrm{C}$ durante quatro semanas, foi observada uma melhora na motilidade espermática em pacientes fumantes. A vitamina $C$ também foi relacionada com o aumento do potencial de fertilização em homens saudáveis, com altos níveis de EOR no sêmem (12). Homens com normospermia, mas com baixas taxas de fertilidade, apresentaram um aumento da capacidade de fertilização prévia in vitro após o tratamento com antioxidantes (8).

A terapia antioxidante pode apresentar efeitos indesejáveis se a dosagem de segurança for ultrapassada. Altas dosagens de vitamina A podem ser embriotóxicas e teratogênicas, causando problemas neurais e anomalias urogenitais e na musculatura esquelética (9). Uma diminuição severa de ON produzida pelos antioxidantes apresenta um reflexo no eixo hormonal da reprodução, com comprometimento na secreção dos hormônios que regulam esta função (8).

\section{Considerações finais}

As taxas de óxido nítrico no líquido seminal são fundamentais para que os espermatozóides tenham plena capacidade de desempenhar sua função de gameta. Quando elevadas, o poder oxidativo do ON não só causa danos à estrutura do gameta como, também, diminui sua mobilidade e sua vitalidade. Mas, em contrapartida, concentrações muito baixas podem dificultar o processo de fertilização e o início da divisão celular do novo embrião. Uma redução do óxido nítrico pode também comprometer a função reprodutiva através da disfunção da regulação do eixo hipotalâmico-hipofisário-testicular.

Portanto o tratamento da infertilidade masculina com terapia antioxidante é bastante promissor, mas deve ser utilizado com moderação, uma vez que as substâncias antioxidantes inibem a formação do ON e comprometem as suas funções fisiológicas.

\section{Referências}

I. Aitken, R.J. Molecular mechanisms regulating human sperm function. Mol. Hum. Reprod., 3(3): 169-73, 1997.

2. Alkan, I. et al. Reactive oxygen species production by the spermatozoa of patients with idiopathic infertility: relationship to seminal plasma antioxidants. J. Urol., 157(1): 140-43, 1997.

3.Amann, R.P.et al. What is semen: how does semen analysis assist in understanding the reproductive status of the male? In: Robaire, B.; Pryor, J.L. \& Trasler, J.M. (eds.) Handbook of andrology. São Francisco: American Society of Andrology, 1995.

4. Austin, C.R. The capacitation of the mammalian sperm. Nature, 170: 326, 1952.

5. Dawson, E.B. et al. Effect of ascorbic acid supplementation on the sperm quality of smokers. Fertil. Steril., 58(5): 1034-9, 1992.

6. De Lamirande, E. \& Gagnon, C. Impact of reactive oxygen species on spermatozoa: a balancing act between beneficial and detrimental effects. Hum. Reprod., I O(suppl. I): I 5-2 I, 1995.

7. Donnelly, E.T. et al. Antioxidant supplementation in vitro does not improve human sperm motility. Fertil. Steril., 72(3): 48495, 1999.

8. Geva, E. et al. The effect of antioxidant treatment on human spermatozoa and fertilization rate in an in vitro fertilization program. Fertil. Steril., 66(3): 430-4, 1996.

9. Hathcock, J.N. Vitamins and minerals: efficacy and safety. Am. J. Clin. Nutr., 66(2): 427-37, 1997.
10. Hellstrom, W.J. et al. Effect of sodium nitroprusside on sperm motility, viability, and lipid peroxidation. Fertil. Steril., 6 I (6): | | 17-22, 1994.

I I. Hermo, L. \& Clermont, Y. How are germ cells produced and what factors control their production? In: Robaire, B.; Pryor J.L. \& Trasler, J.M. (eds.) Handbook of andrology. São Francisco: American Society of Andrology, 1995.

12. Kessopoulou, E. et al. A double-blind randomized placebo crossover controlled trial using the antioxidant vitamin E to treat reactive oxygen species associated to male infertility. Fertil. Steril., 64(4): 825-31, 1995.

13. Knowles, R.G. et al. Formation of nitric oxide from L-arginine in the central nervous system: a transduction mechanism for stimulation of the soluble guanylate cyclase. Proc.Acad. Sci. USA, 86(13): 5159-62, 1989.

14. Kodama, H. et al. Increased oxidative dexyribonucleic acid damage in the spermatozoa of infertile male patients. Fertil. Steril., 68(3): 519-24, 1997.

15. Lewis, S.E. et al. Total antioxidant capacity of seminal plasma is different in fertile and infertile men. Fertil. Steril., 64(4): 86870, 1995.

16. López-Figueroa, M.O. et al. Nitric oxide in the stress axis. Histol. Histopathol., 13(4): 1243-52, 1998.

17. Lowenstein, C.J. et al. Nitric oxide: a physiologic messenger. Ann. Intern. Med., I 20(3): 227-37, 1994.

I 8. McCann, S.M. et al. The role of nitric oxide in reproduction. Braz. J. Med. Biol. Res., 32( I I): I367-79, 1999. 
19. Moira, K.O. et al. Human sperm endothelial nitric oxide synthase expression: correlation with sperm motility. Fertil. Steril., 70(6): I143-47, 1998.

20. Murad, F. Cellular signaling with nitric oxide and cyclic GMP. Braz.J. Med. Biol. Res., 32( I I): I 317-27, 1999.

21. Myles, D.G. How does the spermatozoon make its way to the egg and how does fertilization take place? In: Robaire, B.; Pryor, J.L. \& Trasler, J.M. (eds.) Handbook of andrology. São Francisco: American Society of Andrology, 1995.

22. Nathan, C. Nitric oxide as a secretory product of mammalian cells. Faseb J., 6( | 2): 305 I-64, 1992.

23. Pasqualotto, F.F. et al. Relationship between oxidative stress, semen characteristics, and clinical diagnosis in men undergoing infertility investigation. Fertil. Steril., 73(3): 45964, 2000.

24. Rosselli, M. et al. Effects of nitric oxide on human spermatozoa: evidence that nitric oxide decreases sperm motility and induces sperm toxicity. Hum. Reprod., $10(7)$ : 1786-90, 1995.

25. Stamler, J.S. et al. Biochemistry of nitric oxide and its redoxactivated forms. Science, 18(258): 1898-902, 1992.

26. Tarín, J.J. et al. Antioxidant may protect against infertility. Hum. Reprod., 13(6): 1415-6, 1998.

27. Yanagimachi, R. Fertility of mammalian spermatozoa: its development and relativity. Zygote, 2(4): 371-2, 1994.

28. Zini, A. et al. Reactive oxigen species in semen of infertily patients: levels of superoxide dismutase and catalase like activites in seminal plasma and spermatozoa. Int. J. Androl., 16(3): 183-8, 1993

29. Zirkin, B.R. What is the relationship between the various endocrine components of the male reproductive system? In: Robaire, B.; Pryor, J.L. \& Trasler, J.M. (eds.) Handbook of andrology. São Francisco: American Society of Andrology, 1995. 